\title{
DOUTORAMENTO EM EDUCAÇÃO: SIGNIFICADO E PERSPECTIVAS
}

\section{Doctorate in Education: Meaning and Perspectives $^{1}$}

\author{
Dermeval Saviani ${ }^{2}$
}

\section{Resumo}

Este artigo se propõe a caracterizar, a partir de estudos realizados pelo autor em outras oportunidades, o lugar do doutorado no conjunto da pós-graduação, examinando os problemas, mas também as perspectivas que se abrem para a pós-graduação em educação em nosso país, em particular para a PUCPR. Começando pela caracterização das duas modalidades básicas de pós-graduação, a lato sensu e a stricto sensu, o texto identifica o lugar do doutorado na pós-graduação e destaca seu significado e importância para a educação. Por fim, ao abordar os problemas enfrentados, é apresentada uma análise detalhada daquilo que poderíamos considerar como a mais momentosa questão da atualidade na pós-graduação brasileira: o dilema produtividade-qualidade.

Palavras-chave: Educação brasileira; Pós-graduação em educação; Doutorado em educação; Política de pós-graduação.

\section{Abstract}

The proposal of this article is to characterize, from studies made by the author in other opportunities, the place of the doctorate in the complex of postgraduate courses, examining the troubles and also the perspectives that are open to the post-graduate in education in our country, particularly to the PUCPR. Starting by the characterization of two kinds of post-graduate courses: "lato sensu" and "stricto senso", the text identifies the place of the doctorate in the post-graduate course and shows up its meaning and importance to the education. Finally, the approach of the facing problems is presented by a detailed analysis from what we should consider as the most up dated question currently in the Brazilian post-graduate: productivity-quality dilemma.

Keywords: Brazilian education; Post-graduate in education; Doctorate in education; Post-graduate policy.

1 Conferência Inaugural do Doutorado em Educação da PUCPR - Curitiba, 7 de março de 2007.

2 Doutor em Filosofia da Educação pela PUC-SP e Livre-Docente em História da Educação pela UNICAMP, é Professor Emérito da Unicamp e Coordenador Geral do HISTEDBR. E-mail: dermevalsaviani@yahoo.com.br 
Ao ensejo do honroso convite para proferir esta conferência inaugural das atividades de doutorado do Programa de Pós-Graduação em Educação da Pontifícia Universidade Católica do Paraná, proponho-me a compartilhar com os professores e alunos dessa instituição algumas reflexões que venho desenvolvendo sobre os problemas da pós-graduação em nosso país. Particularmente buscarei caracterizar, a partir de estudos que realizei em outras oportunidades, o lugar do doutorado no conjunto da pós-graduação para, a partir daí, examinar os problemas, mas também as perspectivas que se abrem para a pós-graduação em educação em nosso país, em particular para a PUCPR (SAVIANI, 1991, 2002, 2005).

\section{As duas modalidades básicas de pós-graduação}

Tanto a Lei 4.024/61, a nossa primeira Lei de Diretrizes e Bases da Educação Nacional, como a Lei 5.540/68, a lei da reforma universitária, previam que a universidade, além dos cursos de graduação, poderia organizar cursos de pós-graduação, que seriam oferecidos, como o nome está indicando, a candidatos que tivessem concluído os respectivos cursos de graduação.

Portanto, como sugere a própria nomenclatura, a pós-graduação, considerada em seu conjunto, abrange todos os cursos oferecidos a alunos que já concluíram a graduação. Desse modo, a experiência acabou consagrando a distinção entre duas modalidades básicas de pós-graduação: a lato sensu e a stricto sensu.

Os cursos de pós-graduação lato sensu, embora oferecidos em alguns casos sob a forma de extensão, assumem dominantemente as formas de aperfeiçoamento e especialização e constituem uma espécie de prolongamento da graduação. De fato, esses cursos visam a um aprimoramento (aperfeiçoamento) ou aprofundamento (especialização) da formação profissional básica obtida no curso de graduação correspondente.

Em contrapartida, a pós-graduação stricto sensu, organizada sob as formas de mestrado e doutorado, possui um objetivo próprio, distinto daquele dos cursos de graduação, sendo, por isso mesmo, considerada como a pósgraduação propriamente dita. Nessa condição, diferentemente dos cursos de graduação que estão voltados para a formação profissional, a pós-graduação stricto sensu se volta para a formação acadêmica traduzida especificamente no objetivo de formação de pesquisadores.

Portanto, mesmo supondo-se a situação ideal em que o ensino e a pesquisa são indissociáveis, cabe considerar que a pós-graduação lato sensu tem como elemento definidor o ensino, já que é este que determina o objetivo a ser alcançado, entrando a pesquisa como mediação, certamente necessária, 
para se atingir o objetivo preconizado. Em contraposição, o elemento definidor da pós-graduação stricto sensu é a pesquisa, a qual determina o objetivo a ser alcançado para o qual o ensino concorre como uma mediação destinada a dispor e garantir os requisitos para o desenvolvimento da pesquisa que será a pedra de toque da formação pretendida.

Em razão do acima exposto é que se deu preferência ao termo programa em lugar de curso para a pós-graduação stricto sensu. Essa distinção já se incorporou à história da pós-graduação no Brasil onde, comumente, utilizase a denominação Programa de Pós-Graduação ou Programa de Estudos PósGraduados quando se trata de Mestrado e Doutorado, isto é, da pós-graduação stricto sensu e se usa sempre a denominação Curso de Especialização ou Curso de Aperfeiçoamento quando se trata da pós-graduação lato sensu. A razão dessa distinção reside no fato de que o termo curso se liga diretamente ao ensino e seu centro é um elenco de disciplinas que os alunos devem cursar. Ora, essa é a característica específica da pós-graduação lato sensu. Em contrapartida, a pós-graduação stricto sensu, além do ensino, envolve, como elemento central, a pesquisa. Daí a adoção do termo programa para abarcar tanto as atividades de ensino como de pesquisa. Assim, um Programa de PósGraduação, seja ele de mestrado ou de doutorado ou ambos, tem como centro o programa de pesquisa que o aluno desenvolverá e que deverá resultar na dissertação de mestrado ou tese de doutorado; e, como apoio a essa atividade, ele cursa, também, um elenco de disciplinas disposto em função da área e do tema de sua pesquisa.

A referida distinção, já incorporada à história de nossa pós-graduação, foi também consagrada no texto da nova Lei de Diretrizes e Bases da Educação Nacional, a Lei número 9.394, promulgada em 20 de dezembro de 1996. Esta lei reserva o termo programa para a pós-graduação stricto sensu, utilizando o termo curso para a pós-graduação lato sensu, conforme estipulado no artigo 44:

A educação superior abrangerá os seguintes cursos e programas:

I - cursos seqüenciais por campo de saber, de diferentes níveis de abrangência, abertos a candidatos que atendam aos requisitos estabelecidos pelas instituições de ensino;

II - de graduação, abertos a candidatos que tenham concluído o ensino médio ou equivalente e tenham sido classificados em processo seletivo;

III - de pós-graduação, compreendendo programas de mestrado e doutorado, cursos de especialização, aperfeiçoamento e outros, abertos a candidatos diplomados em cursos de graduação e que atendam às exigências das instituições de ensino (negritos meus). 
IV - de extensão, abertos a candidatos que atendam aos requisitos estabelecidos em cada caso pelas instituições de ensino.

Diante do exposto, entende-se que a proposta de um curso de aperfeiçoamento ou especialização se justifica em conseqüência do avanço do conhecimento decorrente do desenvolvimento da pesquisa na área em questão, cujos resultados afetam o perfil da profissão correspondente. Nesse caso, o curso de pós-graduação lato sensu se proporá a garantir a assimilação dos procedimentos ou resultados do avanço da pesquisa, por parte dos profissionais da área em referência, ajustando o seu perfil às mudanças operadas no perfil da sua profissão. Os programas de pós-graduação stricto sensu, por sua vez, justificam-se não apenas em razão da necessidade de assimilação dos procedimentos e resultados da pesquisa, mas tendo em vista o próprio avanço do conhecimento, isto é, o desenvolvimento das pesquisas numa área determinada, contribuindo diretamente para essa finalidade.

\section{O lugar do doutorado na pós-graduação stricto sensu}

O modelo de pós-graduação adotado no Brasil seguiu deliberadamente a experiência dos Estados Unidos, como se pode observar no texto do Parecer 977/65 que conceituou a pós-graduação onde se encontra um tópico com o seguinte título: Um exemplo de pós-graduação: a norte-americana (BRASIL, 1965, p. 74-79). É com base nessa experiência que se definiu a estrutura organizacional da nossa pós-graduação stricto sensu, centrada em dois níveis hierarquizados, o mestrado e o doutorado, sem, porém, que o primeiro fosse requisito indispensável para o segundo, isto é, o mestrado poderia ser considerado uma etapa preliminar para a obtenção do grau de doutor ou como grau terminal, admitindo-se a possibilidade de inscrição direta no nível de doutorado. Cada um desses níveis compreenderia o estudo de um conjunto de matérias relativas tanto à área de concentração, isto é, o campo específico de conhecimento constitutivo do objeto de estudos escolhido pelo candidato, como ao domínio conexo, ou seja, a área ou áreas de conhecimento correlatas e complementares àquela escolhida pelo aluno. O programa de estudos deveria se completar com a redação de um trabalho resultante de pesquisa, a dissertação, no caso do mestrado e a tese, no caso do doutorado. Assim, a organização dos estudos, embora procurasse se pautar por grande flexibilidade, era bastante clara, envolvendo tarefas bem especificadas e prevendo, inclusive, a figura de um diretor de estudos com a incumbência de assistir e orientar a cada um dos alunos. 
Portanto, se o objetivo precípuo da pós-graduação stricto sensu é a formação do pesquisador, o elemento central em torno do qual ela deve ser organizada é a pesquisa. E como a pós-graduação stricto sensu está organizada em dois níveis, mestrado e doutorado, conclui-se que o primeiro nível tem o sentido de iniciação à formação do pesquisador, reservando-se ao segundo nível a função de consolidação.

Assim, embora seja desejável que a iniciação se dê já no nível da graduação, não parece razoável inscrevê-la como uma exigência obrigatória já nessa primeira etapa do ensino superior. Com efeito, como já foi lembrado anteriormente, o vetor principal dos cursos de graduação é a formação profissional e não a formação de pesquisadores. Por outro lado, mesmo que se atingisse uma difusão bastante ampla da chamada iniciação científica nos cursos de graduação, é lícito supor que sua tarefa não se ligaria diretamente ao objetivo de formação do pesquisador, mas teria antes a finalidade de familiarizar o aluno (o futuro profissional) com os processos e os procedimentos da investigação científica, o que não implicaria necessariamente a realização, por parte de cada um dos alunos, de um projeto próprio e completo de investigação.

No caso do mestrado, porém, a iniciação requerida será feita mediante a realização de um trabalho completo de investigação. Para a maioria dos alunos será, de fato, o primeiro trabalho de pesquisa que ele cumpre, abarcando todas as etapas implicadas no tipo de investigação encetada. Portanto, caberá ao aluno, com o auxílio do orientador e a partir de alternativas delineadas em função do estágio de conhecimento em que se encontra a área correspondente, realizar a escolha do tema, a formulação do problema, a delimitação do objeto assim como o estabelecimento da metodologia e respectivos procedimentos de análise, redigindo, em conseqüência, o texto correspondente com uma estrutura lógica adequada à compreensão plena, por parte dos leitores, do assunto tratado.

O texto referido constitui o que se convencionou denominar de dissertação de mestrado. Supõe, pois, um trabalho relativamente simples, expresso num texto logicamente articulado, ou, como se diz em linguagem corrente, que tem começo, meio e fim, dando conta de um determinado tema. De fato, dissertar significa discorrer, expor, abordar determinado assunto. Distingue-se de tese, denominação reservada ao trabalho do doutorado, já que tese significa posição, sugerindo que a defesa de uma tese é a defesa de uma posição diante de determinado problema. A tese pressupõe, em conseqüência, os requisitos de autonomia intelectual e de originalidade, já que estas são condições para que alguém possa expressar uma posição própria sobre determinado assunto. Ora, tais requisitos não são necessariamente exigidos no caso do mestrado. Supõe-se, antes, que é a conclusão do mestrado que propiciará o 
preenchimento desses requisitos, uma vez que, tendo realizado, com o apoio do orientador, um trabalho completo de investigação, esse exercício nas lides da pesquisa lhe permitirá adquirir um domínio teórico e prático do processo, atingindo, assim, a desejada autonomia intelectual que lhe facultará a formulação original de novos objetos de investigação. Dessa forma, enquanto para o mestrado a autonomia intelectual e a originalidade constituem ponto de chegada, um resultado, para o doutorado esses requisitos se põem no ponto de partida como condições prévias para a realização da etapa final do processo de formação do pesquisador, levado a cabo pelos programas de pós-graduação stricto sen su.

Tendo em vista a exigência apontada, os candidatos aos programas de doutorado necessariamente terão que apresentar, já para o processo de seleção, um projeto próprio de pesquisa, atendendo ao requisito de originalidade, pelo menos em um dos seguintes aspectos: o próprio objeto, investigando algo nunca antes estudado; a forma ou o método, analisando-se um objeto que, embora já estudado por outros, não o fora segundo os procedimentos agora adotados; a perspectiva teórica, que assegurasse o exame de um mesmo objeto sob um ponto de vista ainda não explorado; e as fontes de apoio, isto é, o estudo de um mesmo objeto lançando mão de procedimentos já adotados e sob um ponto de vista também já considerado, baseando-se, porém, em fontes nunca antes utilizadas.

Além disso, os programas têm adotado a prática de exigir, como prérequisito para ingresso no doutorado, o mestrado concluído, embora formalmente isso não seja obrigatório, como se pode notar pela regulamentação da pós-graduação definida pelo Parecer 77/69, também de autoria de Newton Sucupira (BRASIL, 1969, p. 130). Trata-se de uma medida de bom senso, em consonância com a lógica que presidiu a organização da modalidade stricto sensu. Com efeito, como se assinalou, sendo o mestrado o nível de iniciação ao processo de formação do pesquisador; e tendo ele possibilitado a familiarização com o ciclo completo da investigação objetivado na elaboração da dissertação, segue-se que a consolidação da formação do pesquisador deverá estar apoiada no processo de iniciação já realizado no decorrer do mestrado.

\section{Significado e importância do doutorado para a educação}

Como processo de consolidação da formação de pesquisadores, a existência de Programas de Doutorado em Educação estaria sugerindo um nível de maturidade científica atingido pela área de educação, habilitando-se à produção sistemática, constante e continuada de pesquisas envolvendo os aspectos mais significativos da situação educacional. 
Em outros termos, a criação de programas de doutorado reveste-se de caráter estratégico no movimento de passagem da prática educativa do nível do senso comum ao nível científico, colocando em posição central a questão da possibilidade, legitimidade, valor e limites da abordagem científica em educação. Isto porque o próprio tema referente ao estatuto científico da educação é passível de controvérsia. De qualquer modo, pode-se admitir que o desenvolvimento qualitativo aliado ao incremento quantitativo das pesquisas educacionais se encontra em relação direta com a criação, desenvolvimento e expansão dos programas de doutorado em educação. A expectativa é que, ampliando-se a formação dos quadros de pesquisadores qualificados em nível de doutorado, as questões, sejam aquelas de ordem epistemológica relativas ao estatuto teórico da educação, sejam as relativas às prioridades da política educacional que comprimem investimentos em pesquisa pedagógica, tendam a ser equacionadas. A base dessa expectativa reside no fato de que a própria existência de programas de doutorado constitui um indicador da consolidação da área de educação como um campo científico e de pesquisa. E, uma vez consolidada cientificamente, a área adquire um peso maior na disputa pelos recursos disponibilizados pelas agências de ciência e tecnologia para o desenvolvimento de projetos de pesquisa.

No entanto, é preciso ter presente que a relação direta entre a criação de doutorado e o desenvolvimento qualitativo e quantitativo das pesquisas educacionais não se dá necessariamente e de forma automática. Assim, também a expectativa mencionada não está isenta de problemas. Cabe, pois, identificar e analisar tais problemas para poder enfrentá-los. $\mathrm{Na}$ impossibilidade de inventariar, neste texto, os vários problemas, concentrar-me-ei naquele que parece ser o mais destacado na conjuntura atual e que se manifesta na forma de um verdadeiro dilema. Refiro-me ao problema da relação entre produvidade e qualidade na pós-graduação. Retomando os termos de um outro trabalho, abordo, por partes, a questão da produtividade seguida da qualidade para, enfim, analisar o dilema produtividade-qualidade (SAVIANI, 2005).

\section{A questão da produtividade}

A noção de produtividade começou a freqüentar o vocabulário pedagógico a partir da década de 1950 com a divulgação dos trabalhos de Theodore Schultz, conhecidos sob a denominação de "teoria do capital humano". Define-se, a partir daí, uma tendência pedagógica que veio a se tornar dominante no Brasil nos últimos quarenta anos. Trata-se da tendência que poderíamos denominar de "concepção produtivista de educação". 
Na década de 1960, a "teoria do capital humano" foi desenvolvida e divulgada positivamente, sendo saudada como a cabal demonstração do "valor econômico da educação" (SCHULTZ, 1973; 1967). Em conseqüência, a educação passou a ser entendida como algo não meramente ornamental, um mero bem de consumo, mas como algo decisivo do ponto de vista do desenvolvimento econômico, um bem de produção, portanto.

A partir da reforma instituída pela lei n. 5.692, de 11 de agosto de 1971, essa concepção produtivista pretendeu moldar todo o ensino brasileiro por meio da pedagogia tecnicista que, convertida em pedagogia oficial, foi encampada pelo aparelho de Estado que procurou difundi-la e implementá-la em todas as escolas do país. Na medida em que se processava a abertura "lenta, gradual e segura" que desembocou na Nova República, as orientações pedagógicas das escolas foram sendo flexibilizadas, mantendo-se, porém, como diretriz básica da política educacional, a tendência produtivista. É essa visão que, suplantando a ênfase na qualidade social da educação que marcou os projetos da Câmara dos Deputados, constituiu-se na referência para o Projeto Darcy Ribeiro, que surgiu no Senado, sob o patrocínio do MEC, e se transformou na nova Lei de Diretrizes e Bases da Educação Nacional.

Ora, a pós-graduação surge no Brasil precisamente quando a mencionada concepção começa a ganhar corpo em nosso país. É possível, com efeito, encontrar traços dessa tendência no Parecer 977/65, que conceituou a pós-graduação, assim como no Parecer 77/69, que regulamentou a sua implantação, ambos de autoria de Newton Sucupira.

Entretanto, a influência da formação européia dos professores que se responsabilizaram pela condução dos programas de pós-graduação no Brasil os fez trilhar caminhos não propriamente consentâneos com a concepção produtivista. Na verdade, a pós-graduação em educação se tornou o centro da resistência à política oficial, sendo o palco privilegiado dos embates travados na década de 1980 contra a concepção produtivista de educação. E as teorias críticas, primeiro na forma reprodutivista e, depois, tentando superar os limites do reprodutivismo, encontraram um espaço favorável no campo da pósgraduação. Do interior desse campo as teorias críticas buscaram mostrar o caráter ideológico da divulgação positiva da "teoria do capital humano", evidenciando seu caráter negativo enquanto mecanismo de reprodução das condições sociais vigentes e de imposição da ideologia dominante. Mas a referida teoria resistiu a todas essas investidas e, ao recobrar nova força com advento do neoliberalismo ao longo da década de 1990, exerceu seu influxo também sobre a pós-graduação, o que se traduziu nas fortes pressões para torná-la mais produtiva.

É preciso, contudo, observar que, se a concepção produtivista vem se mantendo como dominante ao longo das últimas quatro décadas, não se 
deve considerar que a versão da teoria do capital humano elaborada por Schultz tenha se mantido intacta. Na verdade, essa teoria surgiu no período dominado pela economia keynesiana e pela política do Estado do Bem-Estar que, na chamada era de ouro do capitalismo, preconizavam o pleno emprego. Assim, a versão originária da teoria do capital humano entendia a educação como tendo por função preparar as pessoas para atuar num mercado em expansão que exigia força de trabalho educada. À escola cabia formar a mãode-obra que progressivamente seria incorporada pelo mercado:

o processo de escolaridade era interpretado como um elemento fundamental na formação do capital humano necessário para garantir a capacidade competitiva das economias e, conseqüentemente, o incremento progressivo da riqueza social e da renda individual (GENTILI, 2002, p. 50).

Após a crise da década de 1970, que encerrou a "era de ouro" do desenvolvimento capitalista no século XX, mantém-se a crença na contribuição da educação para o processo econômico-produtivo, mas seu significado foi substantivamente alterado. A teoria do capital humano assume, pois, um novo sentido:

Passou-se de uma lógica da integração em função de necessidades e demandas de caráter coletivo (a economia nacional, a competitividade das empresas, a riqueza social etc.) para uma lógica econômica estritamente privada e guiada pela ênfase nas capacidades e competências que cada pessoa deve adquirir no mercado educacional para atingir uma melhor posição no mercado de trabalho (GENTILI, Op. Cit., p.51).

Nesse novo contexto não se trata mais da iniciativa do Estado e das instâncias de planejamento visando assegurar, nas escolas, a preparação da mão-de-obra para ocupar postos de trabalho definidos num mercado que se expandia em direção ao pleno emprego. Agora é o indivíduo que terá que exercer sua capacidade de escolha visando adquirir os meios que lhe permitam ser competitivo no mercado de trabalho. E o que ele pode esperar das oportunidades escolares já não é o acesso ao emprego, mas apenas a conquista do status de empregabilidade. A educação passa a ser entendida como um investimento em capital humano individual que habilita os indivíduos para a competição pelos empregos disponíveis. O acesso a diferentes graus de escolaridade amplia as condições de empregabilidade do indivíduo o que, entretanto, não lhe garante emprego, pelo simples fato de que, na forma atual do desenvolvimento capitalista, não há emprego para todos: a economia pode crescer convivendo com altas taxas de desemprego e com grandes contingentes populacionais excluídos do 
processo. É o crescimento excludente, em lugar do desenvolvimento inclusivo que se buscava atingir no período keynesiano.

Nessa nova situação, a teoria do capital humano foi refuncionalizada e é nessa condição que ela alimenta a busca de produtividade na educação, de modo geral, e na pós-graduação, em particular. E a pós-graduação, apesar de sua posição privilegiada na pirâmide educacional, nem por isso deixou de ser atingida pela metamorfose que se processou na base da sociedade. Ela também não garante emprego; apenas capacita para a empregabilidade, haja vista os casos recentes e, ao que parece, em número crescente, de doutores desempregados.

Se a expressão "teoria do capital humano" visa alargar o conceito de capital deslocando sua ênfase da produção material para os investimentos no desenvolvimento dos conhecimentos e habilidades humanas, ela também nos obriga a considerar o conceito de produtividade na sua relação com o conceito de capital.

Do ponto de vista capitalista, a produtividade é definida pela valorização do próprio capital, isto é, o seu crescimento por incorporação de mais-valia. Portanto, só é trabalho produtivo aquele do qual resulta diretamente mais-valia:

Somente a estreiteza mental burguesa, que toma a forma capitalista de produção pela forma absoluta, e, em conseqüência, pela única forma natural de produção, pode confundir a questão do que seja trabalho produtivo e trabalhador produtivo do ponto de vista do capital com a questão sobre o que seja trabalho produtivo em geral, contentando-se assim com a resposta tautológica de que é produtivo todo trabalho que produz, todo o que redunda em um produto ou em algum valor de uso qualquer; resumindo: em um resultado (MARX, 1978, p. 71).

Também no caso da pesquisa, da ciência, da produção de conhecimento e, portanto, da pós-graduação, definir a produtividade simplesmente por aquilo que é produzido, isto é, pelo fato de se produzir algo, no caso, conhecimento expresso em dissertações, teses ou relatórios de pesquisa objetivados e divulgados em artigos ou livros, seria cair na mesma tautologia: determinado Programa de Pós-Graduação é produtivo porque produz certa quantidade de dissertações, teses, relatórios, artigos e livros.

Diferentemente desse entendimento tautológico, "o processo capitalista de produção não é simplesmente produção de mercadorias. É processo que absorve trabalho não pago, que transforma os meios de produção em meios de sucção de trabalho não pago" (id. p. 75), o que significa que o "valor de uso específico" do trabalho produtivo para o capital não está no seu caráter de utilidade nem nas "qualidades úteis peculiares ao produto no qual se objetiva”, mas no fato de criar valor de troca, isto é, mais-valia (MARX, 1978, p. 75). 
Como sabemos, o capital tem duas formas de gerar mais-valia: a absoluta e a relativa. No primeiro caso, trata-se de estender o tempo de trabalho para além do tempo necessário para cobrir o custo da força de trabalho. Assim, se o trabalhador necessita trabalhar quatro horas por dia para satisfazer suas necessidades de subsistência, todo o tempo de trabalho que exceder esse limite será trabalho não pago, produtor de mais-valia. Considerada essa hipótese, se a jornada de trabalho for fixada em seis horas, a produtividade do trabalho será de duas horas. Se for fixada em oito ou dez horas, teremos uma produtividade de quatro ou seis horas, e assim sucessivamente.

No segundo caso, trata-se de reduzir o tempo de trabalho necessário para cobrir o custo da força de trabalho, o que só será possível pela introdução de inovações tecnológicas. Desse modo, se a jornada de trabalho tiver atingido um ponto intransponível determinado seja pelo limite físico da duração do dia ( 24 horas) e da necessidade de um mínimo de repouso para os trabalhadores; seja pelo limite social (força organizativa dos trabalhadores que impeça aos capitalistas a ampliação da jornada de trabalho); seja pelo limite político traduzido em leis que impedem a dilatação da jornada, resta aos capitalistas o caminho da mais-valia relativa. Nesse caso, fixada a jornada de trabalho, por exemplo, em oito horas, se a organização do processo de trabalho permitir, pelo incremento tecnológico, a redução da parte paga de quatro para três horas, a produtividade do trabalho será aumentada de quatro para cinco horas e, assim, sucessivamente. Quanto mais a incorporação de inovações tecnológicas permitir reduzir o tempo de trabalho pago, aumentando, conseqüentemente, o tempo de trabalho não pago, maior será a produtividade do trabalho.

Eis por que, no controle dos resultados da pós-graduação, no caso dos docentes, as políticas que foram sendo acionadas cuidaram de aumentar a produtividade das pesquisas, medida pela quantidade acrescida, a cada ano, de produtos objetivados nas publicações. Inversamente, no que se refere à produtividade discente, o aumento foi medido pela redução do tempo gasto na produção de dissertações e teses e, ato contínuo, pela imposição dessa redução no que se refere ao tempo máximo permitido para a obtenção do título acadêmico de mestre ou doutor. Isso porque, nesse último caso, cada aluno de mestrado produz apenas uma dissertação, assim como cada aluno de doutorado produz apenas uma tese. Portanto, o aumento da produtividade está na razão direta da redução do tempo necessário à conclusão desses trabalhos acadêmicos.

\section{A questão da qualidade}

Mas há um aspecto, ao que parece, não advertido pelas políticas produtivistas de pós-graduação e pesquisa: a produção científica e especial- 
mente o ensino de pós-graduação não se identifica inteiramente com a produção material, âmbito em que vigora a lógica férrea do modo de produção capitalista, onde se inspiraram, ainda que não conscientemente, as mencionadas políticas produtivistas. De fato, estamos aí no âmbito da produção nãomaterial, caso em que, segundo Marx, mesmo que se destinem exclusivamente à troca e produza mercadorias, deve-se considerar duas possibilidades:

1) O resultado são mercadorias que existem isoladamente em relação ao produtor, ou seja, que podem circular como mercadorias no intervalo entre a produção e o consumo; por exemplo: livros, quadros, todos os produtos artísticos que se diferenciam da atividade artística do artista executante. A produção capitalista só se aplica aqui em forma muito limitada. Essas pessoas, sempre que não contratem oficiais etc. na qualidade de escultores (sculptors) etc. comumente (salvo se forem autônomos) trabalham para um capital comercial, como, por exemplo, livreiros, uma relação que constitui apenas uma forma de transição para o modo de produção apenas formalmente capitalista. Que nessas formas de transição a exploração do trabalho alcance um grau superlativo, não altera a essência do problema.

2) O produto não é separável do ato de produção. Aqui, também, o modo capitalista de produção só tem lugar de maneira limitada, e pela própria natureza da coisa, não se dá senão em algumas esferas. (Necessito do médico, não de seu moleque de recados). Nas instituições de ensino, por exemplo, os docentes podem ser meros assalariados para o empresário da fábrica de conhecimentos. Não se deve considerar o mesmo para o conjunto da produção capitalista (MARX, 1978, p. 79).

É nesta segunda modalidade que se situa a atividade científica, isto é, a produção de conhecimento (a pesquisa), assim como a educação. Não sendo o produto separável do ato de produção, estamos diante de atividades que não podem ser plenamente objetivadas. Em contrapartida, o conceito de produtividade, tal como formulado pela teoria do capital humano, porque ancorado na produção material, supõe a plena objetivação do trabalho científico e docente. Como isso não é possível, a exigência de aumento de produtividade se choca com a exigência de qualidade da produção acadêmica.

Com efeito, o movimento realizado pelo capital na direção da inteira objetivação do trabalho na produção material tornou possível o incremento da mais-valia relativa pela incorporação de inovações tecnológicas, o que permitiu assegurar, ao mesmo tempo, maior produtividade e maior nível de qualidade dos produtos obtidos. Nesse âmbito, portanto, o aumento da produtividade 
se revela compatível com o aumento da qualidade. Isso porque, promovendo a desqualificação subjetiva dos trabalhadores, a objetivação liberta o processo de produção das interferências aleatórias dos humores subjetivos, sendo a qualidade dos produtos garantida pela organização racional dos meios, por sua vez aprimorados pelo avanço tecnológico. Assim, os ganhos de produtividade se expressam igualmente em ganhos de qualidade.

Espelhando-se nesse processo próprio do trabalho industrial na sociedade capitalista, a concepção produtivista de educação procurou objetivar o trabalho pedagógico. Esse foi o intento da corrente que denominei de "pedagogia tecnicista" que, a partir de 1969, se converteu, no Brasil, em pedagogia oficial. No limite, o anseio dessa corrente pedagógica era garantir a eficiência e a produtividade do processo pedagógico independentemente dos trabalhadores da educação. A eficiência do ensino seria garantida pela racionalização, pelo planejamento do processo sob o controle de técnicos supostamente habilitados, passando os professores a plano secundário, isto é, subordinando-os à organização racional dos meios. Isso, porém, não podia se efetivar tendo em vista a já mencionada impossibilidade da plena objetivação do trabalho educativo já que "a produção capitalista só se aplica aqui em forma muito limitada” (MARX, 1978, p. 79). Daí o fracasso da pedagogia tecnicista que, em nome da racionalidade e da organização, fragmentou o campo pedagógico introduzindo tal grau de descontinuidade que acabou por fazer imperar o caos, gerando, em conseqüência, a irracionalidade e a desorganização, exatamente o contrário do que pretendia. Portanto, a busca de produtividade entrou em contradição com a qualidade. O eventual incremento de produtividade resultou em rebaixamento da qualidade do ensino e dos serviços educacionais.

Essa visão tecnocrática, que no ensino básico reduziu os professores a meros executores de um processo cuja concepção, planejamento, coordenação e controle deles foram subtraídos e enfeixados nas mãos de técnicos, os chamados especialistas em educação, no caso das universidades, em especial as públicas, resultou na idéia segundo a qual a universidade deveria ser o lugar, por excelência, dos especialistas. Aí não haveria espaço para os nãoespecialistas. Portanto, todos os professores deveriam estar contratados em tempo integral com dedicação exclusiva e todos deveriam fazer pesquisa, considerada como o elemento definidor de sua característica de especialistas. Nesse contexto é que a política educacional privilegiou a regulamentação, instalação e consolidação da pós-graduação.

\section{0 dilema produtividade-qualidade}

Considerando-se o caráter da atividade científica e da educação como modalidades de produção não-material, cujo produto não se separa do ato de 
produção; considerando-se que a pesquisa, enquanto atividade científica, e a formação do pesquisador, enquanto atividade educativa, participam dessa característica; considerando-se que a compatibilidade entre a busca de produtividade e a busca da qualidade supõe a plena objetivação do processo de trabalho; considerando-se que a produção não-material não é suscetível de plena objetivação, segue-se que, nas condições próprias da produção nãomaterial, a busca da produtividade entra em contradição com a qualidade dos resultados dessa produção. Está aí a raiz do dilema produtividade-qualidade nos programas de pós-graduação, isto é, no desenvolvimento da pesquisa e na formação do pesquisador.

Dilema é um termo derivado do grego $(\delta \iota \lambda \eta \mu \mu \alpha)$, que é uma palavra composta de dois elementos, a saber: a) a partícula $\delta \mathbf{\imath}$, que, por sua vez, é elisão da preposição e também advérbio dı́a que, no caso, significa "separando", "dividindo", "de um e de outro lado"; b) e o vocábulo $\lambda \eta \mu \mu \alpha$, que singnifica "lema", "tema", "proposição", "premissa de um silogismo". Dilema, portanto, tem o sentido de "premissa dupla", o que levou, também, ao sentido de uma argumentação com duas conclusões contraditórias igualmente possíveis logicamente. A partir dessa acepção técnica, generalizou-se o significado de dilema como expressando uma situação embaraçosa com duas saídas igualmente difíceis.

Vê-se, pois, que, quando falamos do dilema produtividade-qualidade na pós-graduação em educação, estamos falando de uma situação embaraçosa, pois o incremento da produtividade interfere negativamente na qualidade e vice-versa. Assim, ambos os caminhos revelam-se igualmente difíceis. Com efeito, o sentimento geral é que não se pode abrir mão da qualidade, mas também não se pode descuidar da produtividade. Ocorre que esse sentimento generalizado incide naquela "estreiteza mental burguesa", referida por Marx, que se contenta em considerar produtivo todo trabalho que produz alguma coisa, o que, de fato, não passa de uma tautologia. Tal entendimento, obviamente, leva à conclusão que trabalho improdutivo é aquele que nada produz. Assim, resulta evidente que os Programas de Pós-Graduação não podem abrir mão da produtividade, pois isso significaria admitir que ficariam improdutivos, vale dizer, sem produzir coisa alguma. Daí, as classificações tautológicas dos processos de avaliação que chegam a conclusões do seguinte tipo: determinado Programa é muito produtivo porque produz muito; outro é pouco produtivo, pois produz pouco; um terceiro é muito pouco produtivo porque produz muito pouco, e assim sucessivamente. Mas, como pretendi esclarecer neste texto, trabalho produtivo, na sociedade em que vivemos, a sociedade capitalista, é aquele que gera mais-valia e trabalho improdutivo é o que não gera mais-valia o que, evidentemente, não significa que nada produza. Como esclarece Marx, o trabalho produtivo corresponde ao circuito D-M-D' (Dinhei- 
ro-Mercadoria-Capital), isto é, uma situação em que se troca mercadoria por dinheiro enquanto capital, ou seja, a mercadoria é meio para aumentar o capital, para lhe acrescentar valor; ao passo que o trabalho improdutivo corresponde ao circuito M-D-M (Mercadoria-Dinheiro-Mercadoria) em que se troca mercadoria por dinheiro enquanto dinheiro, isto é, o dinheiro obtido pela venda de terminada mercadoria é meio para se adquirir outra mercadoria que venha a satisfazer determinada necessidade de consumo do comprador, não entrando no circuito do capital.

Penso que, à luz das considerações feitas, resulta claro que o manejo do conceito de produtividade no campo da pesquisa e da pós-graduação significa, consciente ou inconscientemente, colocá-las sob a órbita do capital, submetê-las à lógica que rege as relações capitalistas de produção. E isto é, de certo modo, compreensível, pois "o capital é a força econômica da sociedade burguesa que tudo domina" o que faz com que, nesse tipo de sociedade, tudo tende a cair sob a lógica do capital (MARX, 1973, p. 73).

Não obstante essa constatação não se pode desconsiderar o fato de que se trata de um processo contraditório que, no caso em tela, coloca em campos opostos a produtividade e a qualidade da pesquisa e da formação pós-graduada. Como já foi apontado, a exigência de produtividade dificulta a realização da qualidade e a ênfase na qualidade parece não se enquadrar nos critérios correntes de mensuração da produtividade.

O dilema consiste em que, de modo geral, admite-se que os dois aspectos, a produtividade e a qualidade devam integrar o processo de pesquisa e de formação de pesquisadores, mas não sabemos como articulá-los nem qual o peso específico que cada um deles deve ter no referido processo. E quando vislumbramos alguma perspectiva de solução em nível institucional, defrontamo-nos com duas saídas igualmente embaraçosas. Com efeito, poderíamos dar precedência ao primeiro aspecto e, nesse caso, esforçaríamo-nos em atender aos critérios da CAPES e das agências de apoio à pesquisa e à pósgraduação. Assim procedendo, todas as energias da coordenação e corpo docente dos programas de pós-graduação e dos grupos de pesquisa a eles ligados se dirigiriam, por um lado, a aumentar o número de relatórios de pesquisa, encontrar mecanismos de transformá-los em trabalhos apresentados em eventos ditos científicos ou publicados em artigos, livros e capítulos de livros e, por outro lado, a reduzir o tempo destinado à produção de dissertações e teses. Com isso, passariam para segundo plano a relevância, pertinência e consistência dos trabalhos produzidos. A conseqüência seria a queda crescente da qualidade dos Programas de Pós-Graduação. Ou, por outra, poderíamos, dando precedência ao segundo aspecto, voltar todas as atenções e cuidados para o aprimoramento da qualidade, situação em que ficariam em plano subordinado as exigências de produtividade postas pelos órgãos de avaliação e 
financiamento. Aqui, a conseqüência seria a redução do apoio financeiro e de bolsas de estudo, o que acarretaria a queda de produtividade refletindo-se, também, na qualidade da pós-graduação.

As duas saídas resultam, portanto, igualmente problemáticas, mantendo-se, assim, embaraçosa a situação. Como resolver o problema? Como sair do dilema?

Penso que a argumentação desencadeada ao longo desta exposição já indica, de certo modo, as possíveis saídas.

Em termos radicais, a saída se encontra no rompimento com a lógica do capital. Isso implica a transformação das próprias relações de produção, dando origem a um novo tipo de sociedade. Entretanto, mesmo admitindo que essa seja a meta a ser atingida, sabemos que ela não se faz presente em nosso horizonte imediato. Trata-se, assim, de resistir à lógica dominante por meio de diversas ações cujas estratégias devem ser acionadas de acordo com a correlação de forças detectada à luz da análise das situações enfrentadas.

Nessa direção nós podemos, por exemplo, se concluirmos que a correlação de forças é favorável, contestar os critérios de produtividade, mostrar as implicações negativas das exigências feitas pelos órgãos oficiais e, virando o jogo, deixar claro que são esses órgãos que dependem dos Programas e não o contrário, uma vez que é nos Programas de Pós-Graduação que se realizam as atividades-fins e é também daí que provêm os membros das comissões de avaliação e os próprios dirigentes dos órgãos oficiais. Avaliandose, porém, que a correlação de forças não é favorável à estratégia acima indicada, deve-se procurar acionar outros tipos de estratégia.

\section{Conclusão}

Atentos aos problemas enfrentados, os Programas de Doutorado em Educação deverão eleger suas prioridades e perseguir firmemente o objetivo que os justifica, isto é, a consolidação da formação de pesquisadores. A questão da produtividade deverá estar subordinada claramente a esse objetivo e não o inverso, como tem ocorrido atualmente, por efeito da pressão das políticas de investimento. Ou seja, só vale a pena incrementar a produtividade objetivada em relatórios de pesquisa; nas publicações de artigos e livros; nos trabalhos apresentados nos mais diferentes tipos de eventos que se têm multiplicado na área de educação; e nas dissertações e teses, se os produtos em referência configurarem resultados de pesquisas relevantes sobre os problemas prioritários enfrentados pela educação brasileira.

Creio que o Doutorado em Educação da Pontifícia Universidade Católica do Paraná, ao eleger como suas linhas de pesquisa a História articulada às Políti- 
cas Educacionais e a Teoria e Prática Pedagógica na Formação de Professores, circunscreveu as temáticas relevantes de seu esforço investigativo. Nesse âmbito lhe caberá contribuir para a consolidação da formação de pesquisadores do campo educacional, concorrendo, desse modo, para o incremento de uma produção científica qualitativamente significativa sobre os problemas da educação brasileira. Só me resta, pois, parabenizar a coordenação, assim como os professores e alunos que estarão protagonizando essa nova fase da PUCPR, representada pelos estudos pedagógicos pós-graduados em nível de doutorado. Muito obrigado.

\section{Referências}

BRASIL, MEC, CFE (1965), Definição dos cursos de pós-graduação (Parecer n. ${ }^{\circ}$ 977/65). Documenta, 1965, p. 67-86.

BRASIL, MEC, CFE (1969), Normas do credenciamento dos cursos de pósgraduação (Parecer n. ${ }^{\circ}$ 77/69, C.E. Su., aprovado em 11-fevereiro-1969). Documenta, n. 98, p. 128-132, 1969.

GENTILI, Pablo, Três teses sobre a relação trabalho e educação em tempos neoliberais. In: LOMBARDI, J.C.; SAVIANI, D.; SANFELICE, J. L. (Orgs.), Capitalismo, trabalho e educação. Campinas : Autores Associados, 2002. p. 45-59.

MARX, Karl, Contribuição para a crítica da economia política. Lisboa: Estampa, 1973.

MARX, Karl. O Capital (Capítulo VI inédito). São Paulo: Ciências Humanas, 1978.

SAVIANI, Dermeval. A pós-graduação em educação no Brasil: pensando o problema da orientação. In: BIANCHETTI, L. ; MACHADO, A. M. (Orgs.). A bússola do escrever: desafios e estratégias na orientação de teses e dissertações. São Paulo: Cortez, 2002.

SAVIANI, Dermeval. Pesquisa em educação: o dilema produvidade-qualidade na pós-graduação. Aula inaugural do Mestrado em Educação da Universidade Estadual de Maringá (UEM). 2005.

SCHULTZ, Theodore W. O valor econômico da educação. Rio de Janeiro: Zahar, 1967.

SCHULTZ, Theodore W. O capital humano. Rio de Janeiro: Zahar, 1973. 